\title{
Development of a novel integrated membrane system incorporated with an activated coke adsorption unit for advanced coal gasification wastewater treatment
}

\author{
Lili Xu ${ }^{\mathrm{a}, \mathrm{b}, \mathrm{c}}$, Jun Wang ${ }^{\mathrm{a}, \mathrm{b}, *}$, Xiaohui Zhang ${ }^{\mathrm{a}, \mathrm{b}}$, Deyin Hou ${ }^{\mathrm{a}, \mathrm{b}}$, Yang Yu ${ }^{\mathrm{d}}$ \\ a Key Laboratory of Drinking Water Science and Technology, Research Center for Eco-Environmental Sciences, Chinese Academy of Sciences, Beijing 100085, \\ China \\ ${ }^{\mathrm{b}}$ Beijing Key Laboratory of Industrial Wastewater Treatment and Reuse, Research Center for Eco-Environmental Sciences, Chinese Academy of Sciences, \\ Beijing 100085, China \\ ${ }^{\mathrm{c}}$ Membranes@Bath and Department of Chemical Engineering, University of Bath, Bath BA2 7AY, United Kingdom \\ ${ }^{\mathrm{d}}$ Department of Civil and Environmental Engineering, National University of Singapore, 119260, Singapore
}

\section{H I G H L I G H T S}

- Activated coke (AC), a low-cost substitute to the more expensive activated carbon, is firstly used as the pretreatment of integrated membrane processes for the advanced coal gasification wastewater treatment.

- The effect of AC adsorption pretreatment on the UF, RO, and MD units is investigated.

- The mechanism that AC adsorption alleviates membrane fouling is discussed.

- TOC, FEEM, MWD, and GC-MS give a systematic characterization of water quality.

- The techniques that activated coke used as pretreatment of integrated membrane processes has been applied in a local coal gasification plant in China.

\section{A R T I C L E I N F O}

\section{Article history:}

Received 14 June 2015

Received in revised form 26 July 2015

Accepted 29 July 2015

Available online 1 August 2015

\section{Keywords:}

Coal gasification wastewater

Activated coke

Adsorption

Integrated membrane systems
G R A P H I C A L A B S T R A C T

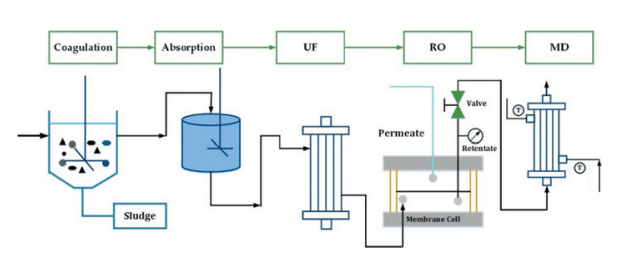

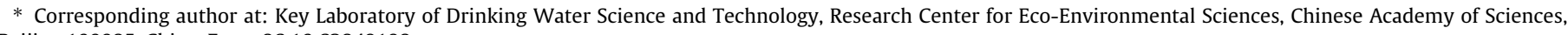
Beijing 100085, China. Fax: +861062849198.

E-mail address: junwang@rcees.ac.cn (J. Wang). 
mitigation was systematically studied with real coal gasification wastewater. The results revealed that majority of the organic matters were effectively removed by the adsorption unit. Consequently, the fouling phenomenon of the subsequent membrane units was suppressed. The permeate fluxes of the UF, RO, and $\mathrm{MD}$ units increased by $31.6 \%, 21.9 \%$, and $23.1 \%$, respectively, when comparing the fluxes between the processes with and without the adsorption unit. The results demonstrated that coupling activated coke adsorption with integrated membrane units was an attractive and feasible option for the advanced treatment of coal gasification wastewater.

(c) 2015 Elsevier B.V. All rights reserved.

\section{Introduction}

Lurgi-Ruhrgas coal gasification process is commonly used to produce large quantity of syngas (methane as the primary component) in the regions rich in coal but poor in oil or gas (e.g., China) [1,2]. The wastewater discharged from the Lurgi-Ruhrgas gasifier usually contains large amount of toxic organic and inorganic pollutants, including phenolic compounds, polynuclear aromatic hydrocarbons, heterocyclic compounds, ammonium, sulfate, cyanide, and thiocyanate which are required to be removed to meet the wastewater discharge regulation $[3,4]$. However, most of the currently available treatment processes, such as anoxic-oxic $(\mathrm{A} / \mathrm{O})$ and anaerobic-anoxic-oxic $\left(\mathrm{A}^{2} / \mathrm{O}\right)$, were proven to be insufficient to reduce these contaminants to an acceptable level $[5,6]$. In this regard, the need for an effective and efficient process to treat the coal gasification wastewater is certainly warranted.

Among all the research efforts aiming for maximally reducing the contaminant contents in the coal gasification wastewater, the so-called "integrated membrane system (IMS)" combining various types of membrane processes and other separation processes has received considerable attention mainly because such an integrated configuration synergistically enhances the advantages of each individual process, and subsequently improves the contaminant removal efficiency from the coal gasification wastewater [7-12]. A typical IMS configuration for coal gasification wastewater treatment consists of a coagulation pre-treatment unit for colloids removal, an ultrafiltration (UF) unit to remove suspended solids, a reverse osmosis (RO) unit for metal ions and small organic matters removal, and a complimentary membrane distillation (MD) unit to further increase the global water recovery of the process. However, despite the great benefits derived from this process, the undesired fouling behavior commonly observed in the UF, RO, and MD unit processes causes a substantially loss in clean water productivity and quality, thus impeding the further advance of IMS in coal gasification wastewater treatment, where large quantity of wastewater is required to be purified and strict discharge regulation needs to be complied with [13-15]. With this concern, developing an appropriate strategy and IMS configuration not only delivering higher contaminant removal efficiency but also suppressing the undesirable membrane fouling phenomenon is of great importance for the IMS process.

The organic matters present in the coal gasification wastewater are believed to be the main foulants that (i) foul the UF membrane thus causing the flux decline in the UF process, (ii) wet the RO membrane surface and consequently lower the salt rejection, and (iii) accumulate on the MD membrane surface thus encouraging the crystallization and scaling of the metal ions on the membrane surface, and consequently lead to a lowered salt rejection. As such, the addition of a pre-treatment step to eliminate these organic foulants thus minimizing the fouling propensity in each individual membrane unit process has become a research focal point and several separation techniques have been considered as the potential pre-treatment candidates. Among them, the use of activated carbon to adsorb contaminant compound (mainly organic matters) in the wastewater shows great process flexibility and potential to be incorporated in the IMS process as a pre-treatment to safeguard the subsequent membrane processes. However, several issues associated with the activated carbon substantially limit the feasibility of using such a material in the wastewater treatment, including: (i) the difficulty to regenerate the activated carbon, and (ii) the high cost of these adsorbents [16-19]. In this regard, it is essential to search for a low-cost, more efficient and easily accessible adsorbent. Activated coke, a low-cost adsorbent, is often used as a substitute adsorbent for activated carbon, due to (i) its excellent $\mathrm{SO}_{X}$ and $\mathrm{NO}_{X}$ adsorption ability in the gas phase, and (ii) its exceptional adsorption capacity to remove organic pollutants from the liquid phase. Furthermore, activated coke is produced from naturally occurring carbonaceous materials such as lignite, petroleum coke, wood and other biomass [16,18,20,21]. Therefore the abundant resource of activated coke in a coal gasification plant guarantees a secured and low-cost supply of such absorbent in the IMS process. However, to the best knowledge of the authors, no studies have yet been reported on the incorporation of an activated coke adsorption unit in an IMS process for the coal gasification wastewater treatment.

In this study, the addition of an adsorption unit with activated coke as a pre-treatment step prior to the UF unit process in a typical IMS configuration was studied. Real coal gasification wastewater provided by a local coal gasification plant instead of synthetic model wastewater was used to demonstrate the feasibility of using such a system in an industrial-relevant environment The effect of the activated coke adsorption pre-treatment on (i) contaminant removal, and (ii) membrane fouling mitigation was systematically examined by comparing the performance of two different IMS configurations (with and without activated coke adsorption unit process). The effluent properties of each unit process were characterized by total organic carbon (TOC), fluorescence excitation-emission matrix (FEEM), molecular weight distribution (MWD), and gas chromatograph/mass spectroscopy (GC-MS) analysis. In addition, the surface morphology of the activated coke as well as the fouling layer formed on the membrane surface was characterized by the scanning electron microscopy (SEM).

\section{Materials and methods}

\subsection{Materials}

The wastewater influent used in the experiments was provided by Yima gasification plant (Henan, China). The existing treatment processes in the plant included a phenolic compounds extraction unit, an ammonia striping unit, and a sequencing batch reactor (SBR) treatment. After being treated by a series of chemical and biological treatments, the wastewater was still deep brown in color with a bad odor. The chemical and physical properties of the wastewater are showed in Table 1.

The activated coke from lignite was obtained from the same gasification plant, with particle sizes ranging from $0.038 \mathrm{~mm}$ to $0.15 \mathrm{~mm}$, and the Brunauer-Emmett-Teller (BET) surface area of 
Table 1

Water quality parameters of the raw wastewater.

\begin{tabular}{|c|c|c|c|}
\hline Parameter & Value & Parameter & Value \\
\hline $\mathrm{pH}$ & $7.1-7.4$ & $\mathrm{Ca}^{2+}(\mathrm{mg} / \mathrm{L})$ & $7.14-7.57$ \\
\hline Conductivity $(\mu \mathrm{S} / \mathrm{cm})$ & $1452-1777$ & $\mathrm{Mg}^{2+}(\mathrm{mg} / \mathrm{L})$ & $6.11-6.56$ \\
\hline $\mathrm{TDS}(\mathrm{mg} / \mathrm{L})$ & $725-888$ & $\mathrm{Al}^{3+}(\mathrm{mg} / \mathrm{L})$ & $1.78-2.04$ \\
\hline Turbidity (NTU) & $44.5-73.7$ & $\mathrm{Cl}^{-}(\mathrm{mg} / \mathrm{L})$ & $48.4-50.8$ \\
\hline $\mathrm{COD}_{\mathrm{cr}}(\mathrm{mg} / \mathrm{L})$ & $342-503$ & $\mathrm{SO}_{4}{ }^{2-}(\mathrm{mg} / \mathrm{L})$ & $463-486$ \\
\hline $\mathrm{TOC}(\mathrm{mg} / \mathrm{L})$ & $138-187$ & $\mathrm{NO}_{3}-(\mathrm{mg} / \mathrm{L})$ & $11.5-12.8$ \\
\hline $\mathrm{NH}_{3}-\mathrm{N}(\mathrm{mg} / \mathrm{L})$ & $8.60-13.2$ & $\mathrm{SiO}_{2}(\mathrm{mg} / \mathrm{L})$ & $18.3-18.5$ \\
\hline
\end{tabular}

$350 \mathrm{~m}^{2} / \mathrm{g}$ (measured by the $\mathrm{N}_{2}$ adsorption isotherms using an ASAP 2000 Micromeritics instrument) (Micromeritics Instrument Corporation, USA). The activated coke was washed with deionized water for several times to remove the contaminants attached on the surface until the washed water became visibly clear. The activated coke was then dried in an oven at $105^{\circ} \mathrm{C}$ for $48 \mathrm{~h}$ and stored in an air-tight glass bottle for further use.

\subsection{Experimental}

\subsubsection{Process 1: Coagulation-UF-RO-MD}

The Process 1 consisted of a coagulation unit, followed by a UF unit, a RO unit, and finally a MD unit, a schematic representation of the entire IMS process is provided in Fig. 1.

In the coagulation unit, polyaluminum chloride (PAC, flocculant) and polyacrylamide (PAM, coagulant) were added with a dosage of $250 \mathrm{mg} / \mathrm{L}$ and $1.0 \mathrm{mg} / \mathrm{L}$, respectively. The coagulation process was performed on an agitation apparatus (MY3000-6G, Meiyu Environmental Equipment Corporation, China). PAC was firstly added in the wastewater $(1 \mathrm{~L})$, after 1 min of vigorous mixing at $250 \mathrm{rpm}$, PAM was then added in the wastewater. The wastewater samples were then subjected to a three-step agitation: a 1 min rapid mixing at $150 \mathrm{rpm}$, followed by a $10 \mathrm{~min}$ slow mixing at $60 \mathrm{rpm}$ and a $5 \mathrm{~min}$ slow mixing at $30 \mathrm{rpm}$. The samples were then allowed for precipitation for $30 \mathrm{~min}$, the supernatant was collected at the end of the 30 min precipitation and used as the feed for the UF process.

A polysulfone (PSf) hollow fiber UF membrane module (GHF3540, Gohigher Environmental Tech, China) with a molecular weight cut-off (MWCO) of 20-30 kDa was used in the UF unit process in a cross-flow configuration at 0.50 bar. The retentate stream of the UF process was recirculated back to the feed tank, whilst the permeate stream was used as the feed of the subsequent RO process.

In the RO unit, a laboratory-scale cross-flow filtration setup (CEPA CF II, GE Osmonics, USA) consisting of a feed tank, a pump, a pressure gauge and a membrane filtration cell was used, and the flat-sheet RO membrane (BW30-4040) was provided by FilmTec Corporation, USA. The new membrane was pre-compacted for $24 \mathrm{~h}$ by filtering with deionized water until a steady-state flux was obtained. The feed solution was stored in a $4 \mathrm{~L}$ reservoir and pressurized to 10 bar before pumping into the RO membrane unit, whilst the retentate stream was recirculated back to the feed reservoir. The weight of the permeate was continuously monitored with a digital balance (ML3002, Mettler-Toledo Corporation, Switzerland) to observe the flux decline behavior. Water recovery was limited to $75 \%$ to avoid the precipitation of soluble salts on the membrane surface. The RO brine was then sent to the MD unit to be desalinated and concentrated.

Microporous polyvinylidene fluoride (PVDF) hollow fiber membrane (provided by Tianjin Polytechnic University, Tianjin, China) was used in the MD unit process. The feed and permeate temperatures were set at $323 \mathrm{~K}$ and $298 \mathrm{~K}$, respectively, and the flow rates of the feed and permeate streams were maintained at $0.5 \mathrm{~m} / \mathrm{s}$ and $0.1 \mathrm{~m} / \mathrm{s}$. A bore side feed configuration was used in this study. During the first $24 \mathrm{~h}$ of the experiment, both permeate and retentate streams were recirculated back to the feed tank, then the permeate was collected in a separate reservoir where the weight and the conductivity of the permeate were measured by a digital balance (ML3002, Mettler-Toledo Corporation, Switzerland) and a conductivity meter (Thermo's Orion 145A+, USA), respectively.

\subsubsection{Process 2: Coagulation-activated coke adsorption-UF-RO-MD}

The set-up for Process 2 was similar to that of Process 1, with the additional activated coke adsorption unit prior to the UF unit process (Fig. 2). In the activated coke adsorption unit, $75 \mathrm{~g}$ activated coke was added into a feed tank containing $5 \mathrm{~L}$ of coagulant effluent with an Electric mixer (JJ-1, Ronghua Equipment Corporation, China). After $2 \mathrm{~h}$ of adsorption (preliminary experiments revealed that the adsorption equilibrium was reached within $2 \mathrm{~h}$ ), the water sample was settled for $12 \mathrm{~h}$ and then the supernatant was provided as the feed of the UF unit process.

\subsection{Analytical methods}

\subsubsection{Wastewater quality measurement}

China national standard methods were adopted to measure and determine the chemical and physical properties of the coal gasification wastewater. The $\mathrm{pH}$ and turbidity were determined using a pH meter (FE20-FiveEasy, Mettler-Toledo Corporation, Switzerland) and a turbidimeter (Hach 2100, Hach Corporation, USA). The total organic carbon (TOC) was monitored using a TOC analyzer (Torch, Tekmar Dohrmann Corporation, USA). The chemical oxygen demand (COD) was measured by the titrimetric method using dichromate as the oxidant in acidic solution at $150^{\circ} \mathrm{C}$ for $2 \mathrm{~h}$ (Hach heating system, Hach Corporation, USA). The concentration of $\mathrm{NH}_{3}-\mathrm{N}$ was obtained through Nessler's reaction using a 722S spectrophotometer (Jingke Equipment Corporation, China). The iron content was measured using the inductively coupled plasma atomic emission spectroscopy (ICP-AES) (Prodigy, Leeman Corporation, USA) and the ion chromatograph (ICS-1000, Dionex Corporation, USA). All the chemicals used in the experiments were with analytic grade.

\subsubsection{FEEM analysis}

The FEEM spectra of the wastewater samples were recorded with a fluorometer (F-7000, Hitachi, Japan). A 450-W Xenon lamp was used as the excitation source. FEEM were collected every $5 \mathrm{~nm}$ over an excitation (Ex) range of 200-400 nm, with an emission (Em) range of $280-550 \mathrm{~nm}$ by $5 \mathrm{~nm}$. The spectra were obtained by subtracting the Milli-Q water blank spectra, recorded under the same conditions, to eliminate water Raman scatter peaks. The software Origin 8.5 (OriginLab Inc., USA) was used to process the data. The $X$-axis indicates the emission spectra from $300 \mathrm{~nm}$ to $550 \mathrm{~nm}$ while the $Y$-axis represents the excitation from $200 \mathrm{~nm}$ to $400 \mathrm{~nm}$, and the contour line as the third dimension, is given to express the fluorescence intensity.

\subsubsection{Molecular weight distribution (MWD) analysis}

MWD was measured using a laboratory-scale membrane separation apparatus (Minimate TFF system, Pall Corporation, USA). The wastewater was first filtrated through a $0.45 \mu \mathrm{m}$ cellulose acetate membrane, and then followed by the filtration through a series of ultrafiltration membranes with different molecular weight cut-off (MWCO) from 650 Da to 30,000 Da (Minimate TFF capsule, Pall Corporation, USA). The membranes were washed with deionized water for at least $24 \mathrm{~h}$ prior to use.

\subsubsection{GC-MS analysis}

GC-MS was used for organic compound analysis. The samples were pretreated by liquid-liquid extraction using $\mathrm{CH}_{2} \mathrm{Cl}_{2}$ 


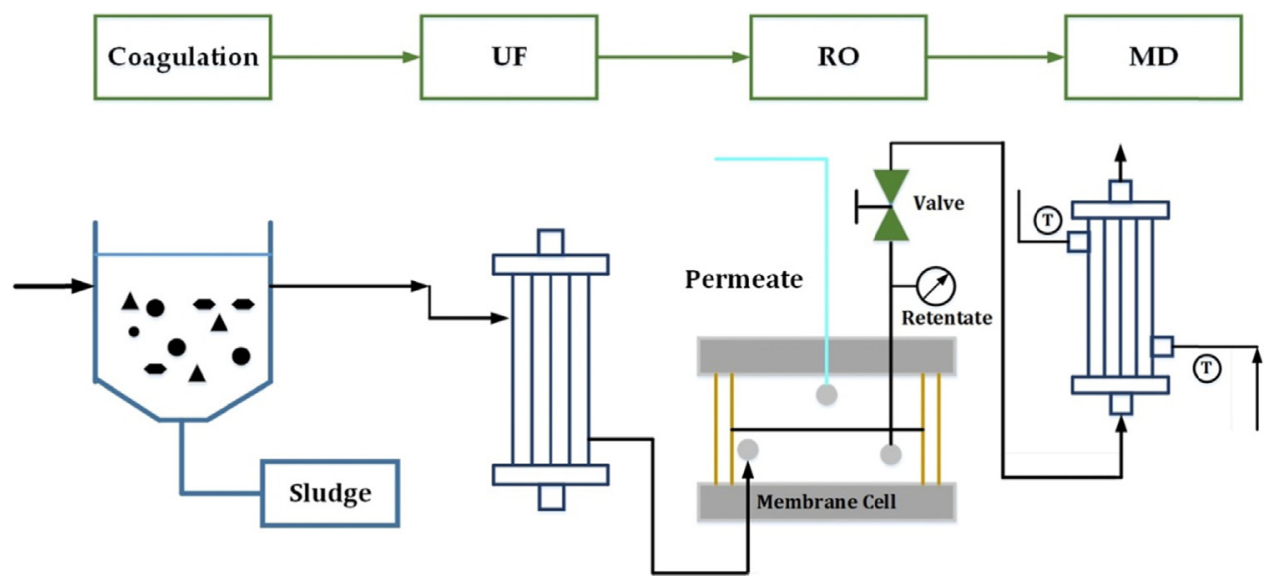

Fig. 1. Schematic representation of the IMS process in Process 1.

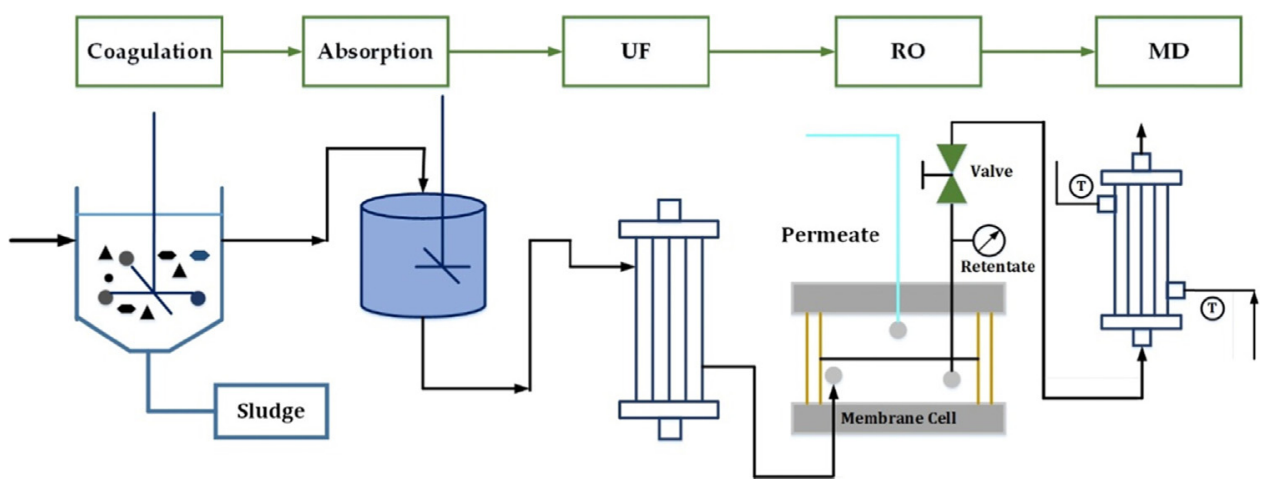

Fig. 2. Schematic representation of the IMS process in Process 2.

(chromatogram pure grade, Fisher Corporation, USA). Then, $1 \mu \mathrm{L}$ pretreated sample was analyzed using a 6890N/5973 GC-MS system (Agilent Corporation, USA), coupled with a DB-35MS capillary column with the inner diameter of $0.25 \mathrm{~mm}$ and the length of $30 \mathrm{~m}$. The temperature of the gasification compartment was maintained at $280^{\circ} \mathrm{C}$. The temperature was first set at $40^{\circ} \mathrm{C}$ for $3 \mathrm{~min}$ and then increased to $280^{\circ} \mathrm{C}$ with an increment of $3^{\circ} \mathrm{C} / \mathrm{min}$. The electron energy and the electron double voltage were set at $70 \mathrm{eV}$ and $1200 \mathrm{~V}$, respectively, and the molecular weight scan varied from 50 Da to 800 Da.

\subsubsection{SEM analysis}

The surface morphology of the activated coke and the fouling cake layer formed on the membrane surface was studied using scanning electron microscopy (S-3000N, Hitachi Company, Japan).

\section{Results and discussion}

\subsection{Pollutants removal efficiency in each unit of two different} processes

Fig. 3 presents the TOC and turbidity results in each unit of the two different processes. In terms of the TOC, it was found that the coagulation unit substantially reduced the TOC level from $152 \mathrm{mg} / \mathrm{L}$ to $87.4 \mathrm{mg} / \mathrm{L}$, whilst the subsequent UF process only slightly reduced it to $75.3 \mathrm{mg} / \mathrm{L}$ in the case of Process 1 where no adsorption unit was added. On the other hand, in the case of Process 2 , a sharp drop in TOC from $87.4 \mathrm{mg} / \mathrm{L}$ (after coagulation) to $12.3 \mathrm{mg} / \mathrm{L}$ (after adsorption) was observed due to the addition of the activated coke adsorption unit. Similarly, the subsequent UF unit in Process 2 only managed to further reduce TOC from $12.3 \mathrm{mg} / \mathrm{L}$ to
$11.8 \mathrm{mg} / \mathrm{L}$. Such a high TOC removal efficiency of the activated coke adsorption (up to 85.9\%), along with the low TOC removal efficiency of UF process suggested that a large number of organic matters and colloids that cannot be effectively removed by UF membranes due to the relatively smaller particle size than the pore size of UF membrane, can be instead, sufficiently removed by the activated coke adsorption. The similar level of TOC after the RO unit in both processes indicated that the RO process alone is also capable of removing the majority of the organic matters, similar to that of the adsorption unit. However, it should be noted that the organic matters present in the wastewater stream is the main foulant contributing to the undesired fouling behavior as aforementioned. As such, the addition of an activated coke adsorption unit prior to the UF unit not only functioned as an additional step to better remove contaminants, but also served as a safeguard to prevent the subsequent membrane processes (UF, RO, and MD) from undesired fouling. In terms of the effluent turbidity, similar trend in comparison with TOC was observed with the additional adsorption unit, suggesting the excellent adsorption efficiency of the activated coke.

\subsection{Mechanism of the organic pollutants removal in the activated coke adsorption unit}

The results presented in Fig. 3 clearly indicate that the activated coke can sufficiently adsorb a large amount of organic matters in the wastewater. To better reveal the removal mechanism of the adsorption unit, a variety of characterization techniques were applied, and the results are presented in this section. 


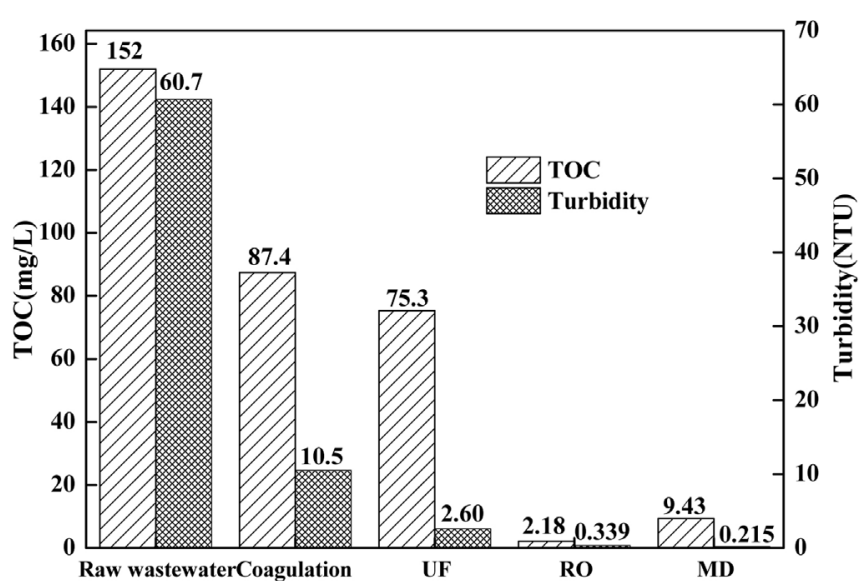

(a) Process 1

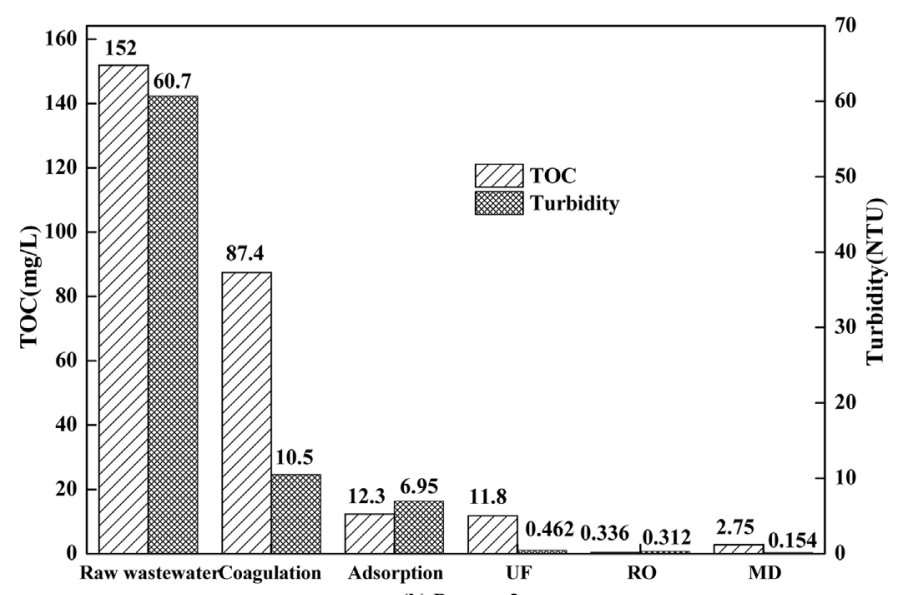

(b) Process 2

Fig. 3. TOC and turbidity in each unit of two different processes (a) Process 1 and (b) Process 2.

\subsubsection{FEEM spectra analysis}

Fig. 4 shows the fluorescence spectra of the raw wastewater, coagulation effluent and adsorption effluent. Region I, II, III, and IV represents aromatic protein, fulvic acid-like organics, humic acid-like organics, and soluble microbial by-product-like materials, respectively [22]. The raw wastewater contained all the above mentioned pollutants. After coagulation, the florescence intensities decreased but it was still difficult for the coagulation unit to efficiently remove the pollutants. This was also consistent with some previous studies, which reported that many humic and fulvic acid substances derived from raw wastewater and some soluble microbial product produced during biodegradation could not be effectively removed by coagulation [23-25]. However, significant variations were observed after the AC adsorption unit. Two peaks associated with humic acid and fulvic acid compounds disappeared, indicating that AC effectively absorbed the refractory organics. The adsorption effluent only contained aromatic protein and soluble microbial by-product-like materials with decreased concentration.

\subsubsection{MWD analysis}

The molecular weight distribution of the raw wastewater, coagulation, and adsorption effluents are shown in Fig. 5. It was clear that the majority compounds presented in the raw wastewater had a molecular weight either higher than $30,000 \mathrm{Da}$ or less than $10,000 \mathrm{Da}$. Furthermore, it appeared that the coagulation unit displayed exceptional removal capability for compounds with molecular weights higher than $30,000 \mathrm{Da}$, and mediocre efficiency for removing compounds with molecular weights less than

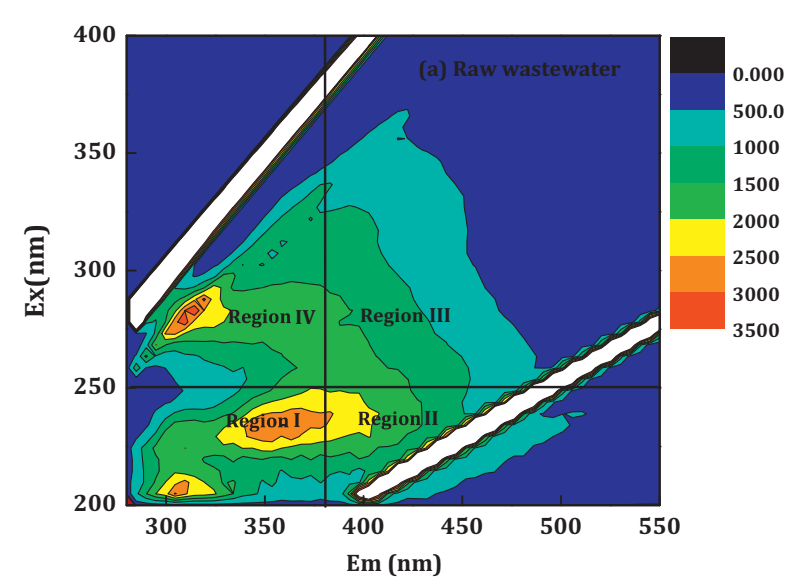

(a) Raw wastewater

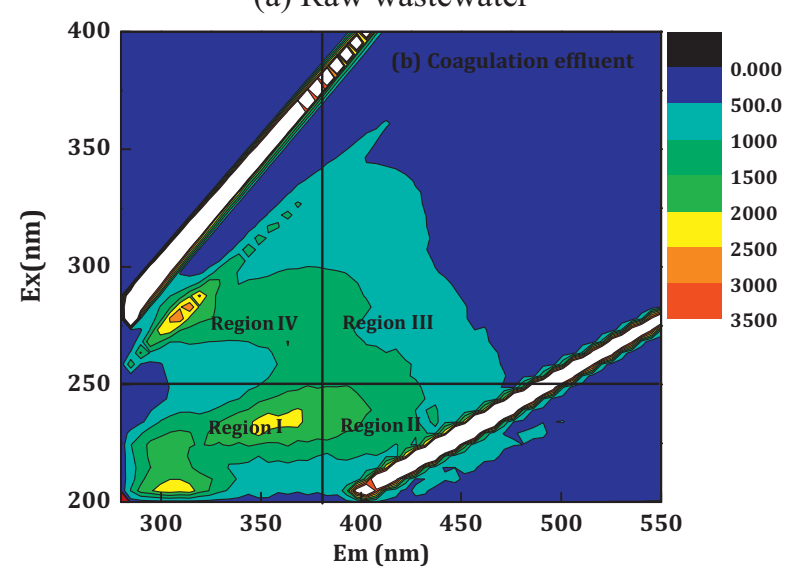

(b) Coagulation effluent

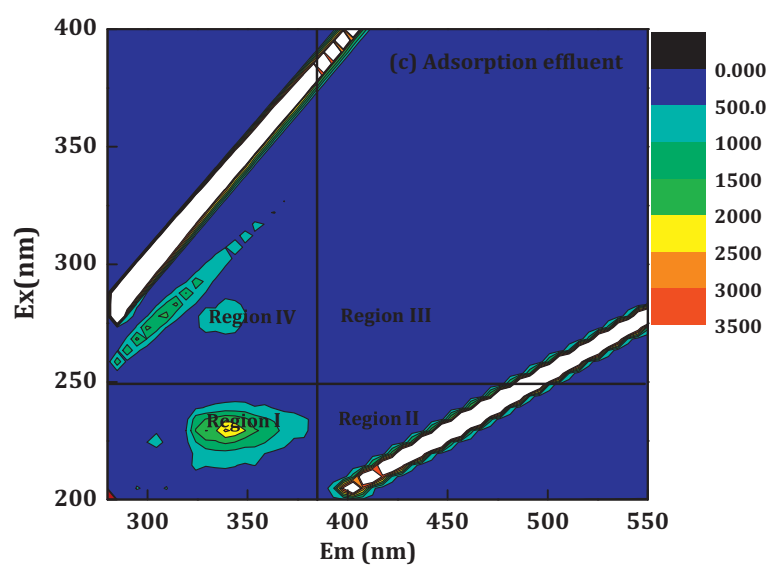

(c) Adsorption effluent

Fig. 4. FEEM spectra of wastewater: (a) raw wastewater, (b) coagulation effluent, and (c) adsorption effluent.

10,000 Da. After adsorption, contaminants with molecular weight more than 3000 Da have been removed effectively. Combined with the FEEM analysis, it can be concluded that the contaminants mainly included refractory humic acid and fulvic acid compounds. These compounds imposed significant fouling propensity on membrane system reported by numerous studies [26-31]. The fouling study was also performed in this work and the results will be presented in the following sections to reveal the effect of the additional adsorption unit on the fouling behavior of the subsequent membrane units. 


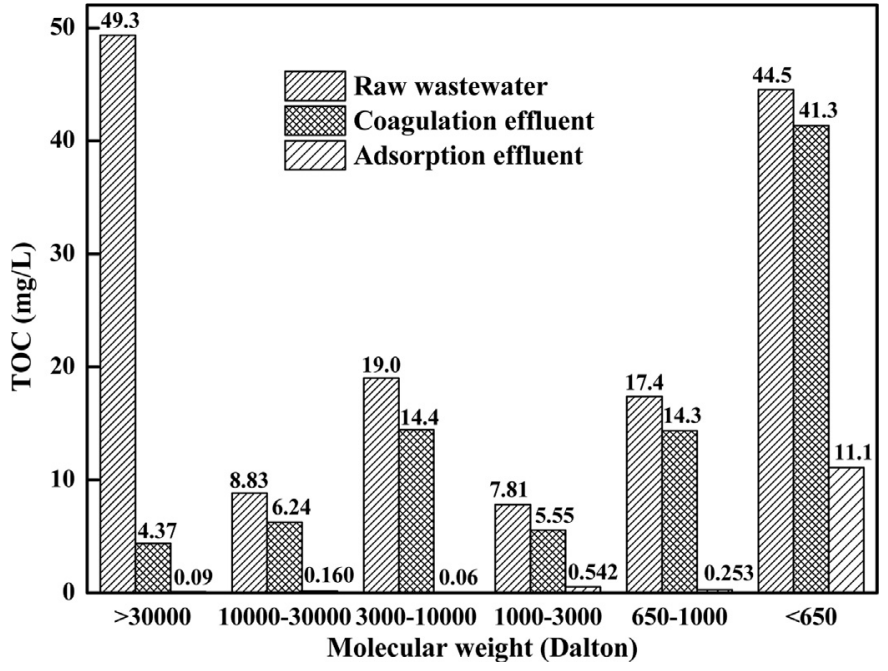

Fig. 5. MWD in the raw wastewater, coagulation effluent, and adsorption effluent.

\subsubsection{GC-MS analysis}

Tables 2 and 3 show the organic compositions of the coagulation and activated coke adsorption effluent, respectively. MWD results from Fig. 5 illustrated the presence of a large portion of refractory organic compounds with molecular weight less than $30,000 \mathrm{Da}$ in the coagulation effluent. As shown in Table 2, these compounds were mainly ketones, heterocyclic compounds, alcohols, eaters and benzenes, which could lead to membrane fouling on the RO and MD units. As a result of the activated coke adsorption, majority of the heterocyclic compounds were removed and only little ketones, alcohols, esters, and benzenes were still detected in the effluent (Table 3). These residual contaminants were mainly from aromatic protein and soluble microbial by-product-like materials with a molecular weight less than $650 \mathrm{Da}$.

\subsection{Effect of adsorption pretreatment on the fouling behavior of the IMS}

\subsubsection{Effect of adsorption pretreatment on the fouling behavior in} the UF unit

Fig. 6 shows the normalized flux $\left(J / J_{0}\right)$ and trans-membrane pressure (TMP) profiles as a function of time in the UF unit of two different processes. The results clearly indicated that in the case of no additional adsorption unit, the permeate flux sharply dropped by $24.0 \%$ and the TMP increased by $66.0 \%$ (from 0.50 bar to 0.83 bar), suggesting the occurrence of severe fouling. On the other hand, when the adsorption unit was introduced, the permeate flux remained almost constant and the TMP only increased by $12.0 \%$ (from 0.50 bar to 0.56 bar). These results indicated that the activated coke adsorption unit effectively removed contaminants responsible for fouling; consequently, the fouling behavior in the subsequent UF process was significantly mitigated.

\subsubsection{Effect of adsorption pretreatment on the fouling behavior in the RO unit}

Fig. 7 shows the normalized flux $\left(J / J_{0}\right)$ as a function of time in the RO units of two different processes. It can be seen that the normalized flux in both cases decreased over time. More specifically, a more pronounced flux decline was observed in the IMS process without the adsorption pretreatment. At the end of operation cycle, the normalized fluxes of Processes 1 and 2 decreased by $28.0 \%$ and $11.4 \%$, respectively. The fouling of the RO membrane was caused by the accumulation of organic and inorganic matters on the membrane surface that cannot be effectively removed by the preceding

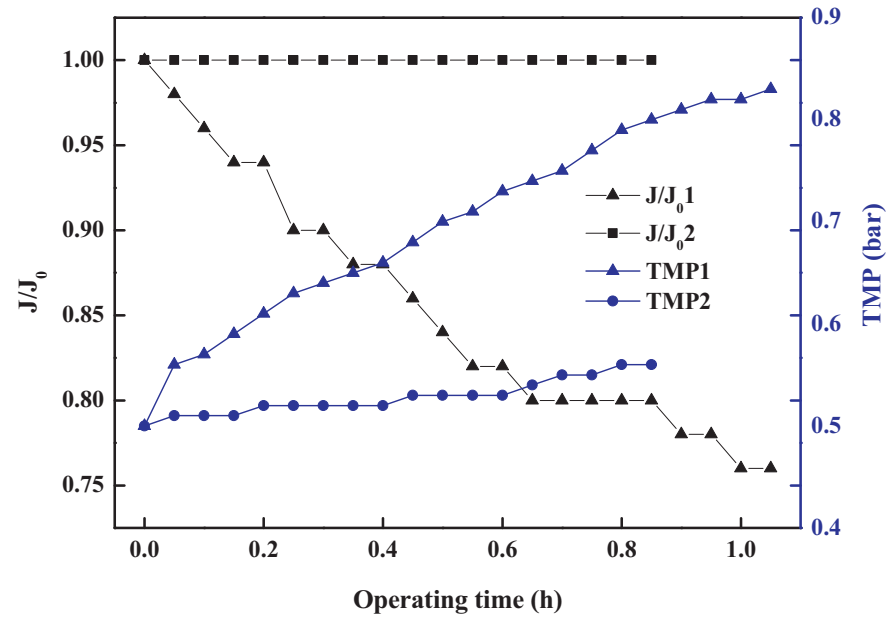

Fig. 6. Normalized flux $\left(J / J_{0}\right)$ and TMP as a function of time in the UF units of two different processes $\left(J / J_{0} 1\right.$ was the UF membrane flux decline without AC adsorption pretreatment; $J / J_{0} 2$ was the UF membrane flux decline with AC adsorption pretreatment; TMP1 was the trans-membrane pressure of UF without AC adsorption pretreatment; TMP2 was the trans-membrane pressure of UF with AC adsorption pretreatment).

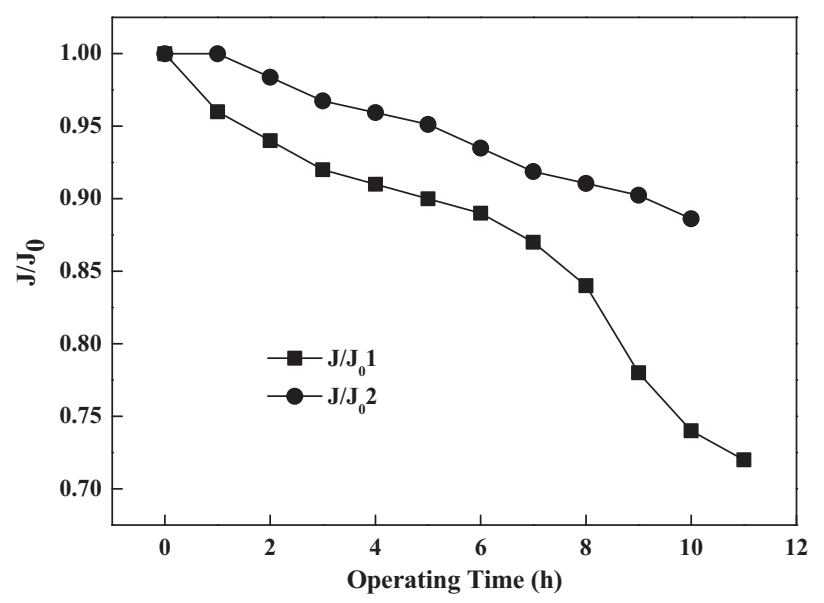

Fig. 7. Normalized flux $\left(J / J_{0}\right)$ as a function of time in the RO units of two different processes $\left(J / J_{0} 1\right.$ was RO membrane flux decline without AC adsorption pretreatment; $J / J_{0} 2$ was RO membrane flux decline with AC adsorption pretreatment).

UF process. As such, the result demonstrated in Fig. 7 also indicated that the activated coke adsorption showed great influence not only on the following UF process but also on the RO unit further downstream.

\subsubsection{Effect of adsorption pretreatment on the fouling behavior in the MD unit}

Fig. 8 shows the normalized flux and the conductivity profile as a function of time in the MD units of two different processes. Similar to the observations in the UF and RO processes, a much more moderate flux decline was observed in the MD process when the activated coke adsorption unit was included, suggesting the suppression of the fouling behavior due to the removal of foulants in the adsorption unit.

In terms of the conductivity profiles in two processes, it was found that the conductivity of the permeate streams increased sharply in the initial stage of the MD process, suggesting that some metal ions have penetrated into the distillate. Furthermore, the maximal conductivity for Processes 1 and 2 were found to be $140.1 \mathrm{mS} / \mathrm{cm}$ and $122.3 \mathrm{mS} / \mathrm{cm}$, respectively. Afterward, a gradual decrease in conductivity was observed for both processes. Through 
Table 2

GC-MS analysis of the coagulation effluent.

\begin{tabular}{|c|c|c|c|}
\hline Number & Organic compounds in coagulation effluent & Formula & Relative content (\%) \\
\hline 1 & 2-Methyl-1,3-cyclopentanedione & $\mathrm{C}_{6} \mathrm{H}_{8} \mathrm{O}_{2}$ & 21.1 \\
\hline 2 & 5-Methyl-isothiazole & $\mathrm{C}_{4} \mathrm{H}_{5} \mathrm{NS}$ & 18.8 \\
\hline 3 & Dibutyl phthalate & $\mathrm{C}_{16} \mathrm{H}_{22} \mathrm{O}_{4}$ & 10.3 \\
\hline 4 & 2,2,6,6-Tetramethyl-4-piperidone & $\mathrm{C}_{9} \mathrm{H}_{17} \mathrm{NO}$ & 9.9 \\
\hline 5 & 1,2-Benzenedicarboxylic acid bis(2-methylpropyl) ester & $\mathrm{C}_{16} \mathrm{H}_{22} \mathrm{O}_{4}$ & 6.1 \\
\hline 6 & 4-Butyl-benzenamine & $\mathrm{C}_{10} \mathrm{H}_{15} \mathrm{~N}$ & 4.8 \\
\hline 7 & Benzothiazole & $\mathrm{C}_{7} \mathrm{H}_{5} \mathrm{NS}$ & 4.2 \\
\hline 8 & 2,3-Dimethyl-3-buten-2-ol & $\mathrm{C}_{6} \mathrm{H}_{12} \mathrm{O}$ & 4 \\
\hline 9 & 2-Methylpiperidine & $\mathrm{C}_{6} \mathrm{H}_{13} \mathrm{~N}$ & 3.7 \\
\hline 10 & 4-Hydroxy-3-methoxy-benzonitrile & $\mathrm{C}_{8} \mathrm{H}_{7} \mathrm{NO}_{2}$ & 3.2 \\
\hline 11 & 2-Aminopyridine & $\mathrm{C}_{5} \mathrm{H}_{6} \mathrm{~N}_{2}$ & 3.1 \\
\hline 12 & 5,6,7,8-Tetrahydro-2-naphthalenol & $\mathrm{C}_{10} \mathrm{H}_{12} \mathrm{O}$ & 2.7 \\
\hline 13 & Alpha,alpha-dimethyl-benzenemethanol & $\mathrm{C}_{9} \mathrm{H}_{12} \mathrm{O}$ & 2.1 \\
\hline 14 & 5-Acetyl-2-methylpyridine & $\mathrm{C}_{8} \mathrm{H}_{9} \mathrm{NO}$ & 2 \\
\hline 15 & 1,2-Benzenedicarboxylic acid diisooctyl ester & $\mathrm{C}_{24} \mathrm{H}_{38} \mathrm{O}_{4}$ & 1.7 \\
\hline 16 & Tetramethyl-thiourea & $\mathrm{C}_{5} \mathrm{H}_{12} \mathrm{~N}_{2} \mathrm{~S}$ & 1.3 \\
\hline 17 & Butylated hydroxytoluene & $\mathrm{C}_{15} \mathrm{H}_{24} \mathrm{O}$ & 1 \\
\hline Total TOC & & & \\
\hline
\end{tabular}

Table 3

GC-MS analysis of the AC adsorption effluent

\begin{tabular}{|c|c|c|c|}
\hline Number & Organic compounds in AC adsorption effluent & Formula & Relative content (\%) \\
\hline 1 & 1,2-Benzenedicarboxylic acid diisooctyl ester & $\mathrm{C}_{24} \mathrm{H}_{38} \mathrm{O}_{4}$ & 50.8 \\
\hline 2 & Butylated hydroxytoluene & $\mathrm{C}_{15} \mathrm{H}_{24} \mathrm{O}$ & 14.5 \\
\hline 3 & Dibutyl phthalate & $\mathrm{C}_{16} \mathrm{H}_{22} \mathrm{O}_{4}$ & 13.8 \\
\hline 4 & 2,2,6,6-Tetramethyl-4-piperidinone & $\mathrm{C}_{9} \mathrm{H}_{17} \mathrm{NO}$ & 8.7 \\
\hline 5 & 1,2-Benzenedicarboxylic acid, bis (2-methylpropyl) ester & $\mathrm{C}_{16} \mathrm{H}_{22} \mathrm{O}_{4}$ & 7 \\
\hline 6 & Alpha,alpha-dimethyl-benzenemethanol & $\mathrm{C}_{9} \mathrm{H}_{12} \mathrm{O}$ & 4.2 \\
\hline 7 & Tetramethyl-thiourea & $\mathrm{C}_{5} \mathrm{H}_{12} \mathrm{~N}_{2} \mathrm{~S}$ & 1 \\
\hline \multicolumn{4}{|c|}{ Total TOC $(\mathrm{mg} / \mathrm{L}) 12.3$} \\
\hline
\end{tabular}

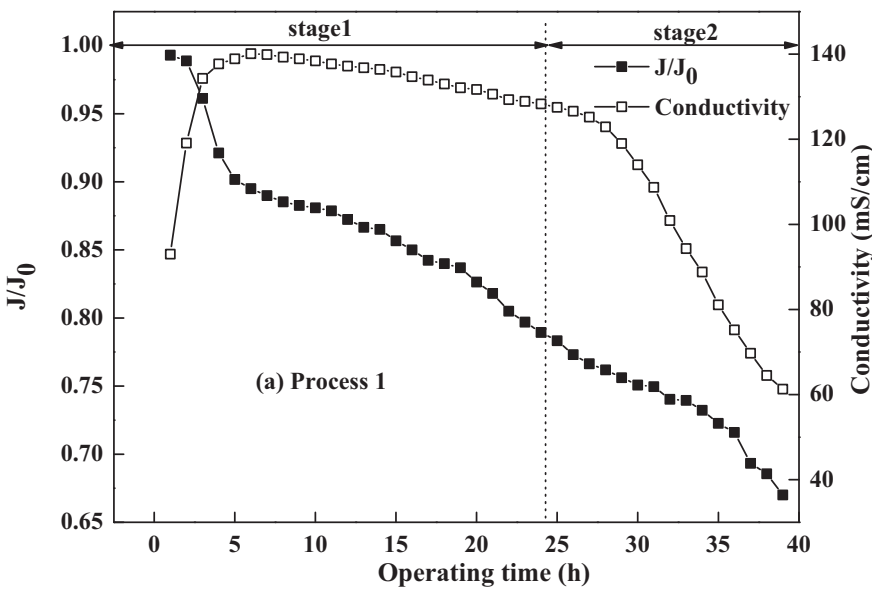

the analysis of MD distillate, only $\mathrm{Ca}^{2+}, \mathrm{SO}_{4}{ }^{2-}, \mathrm{NO}_{3}{ }^{-}$, and $\mathrm{Cl}^{-}$were presented and the total concentration of these inorganic ions were $10.6 \mathrm{mg} / \mathrm{L}$ for Process 1 and $4.38 \mathrm{mg} / \mathrm{L}$ for Process 2 , which shall only lead to a very low conductivity. Therefore the increase of the distillate conductivity in the initial stage of the both processes (as shown in Fig. 8) could be a result of penetration of the volatile organic compounds from the feed to the distillate [32]. Once the diffusion of volatile organic compounds was complete, the conductivity of the distillate stream began to decrease over the remaining period of operation time. The slightly lower maximal conductivity and final conductivity at the end of the MD operation in the case of Process 2 suggested that a portion of the volatile organic compounds were removed in the activated coke adsorption unit.

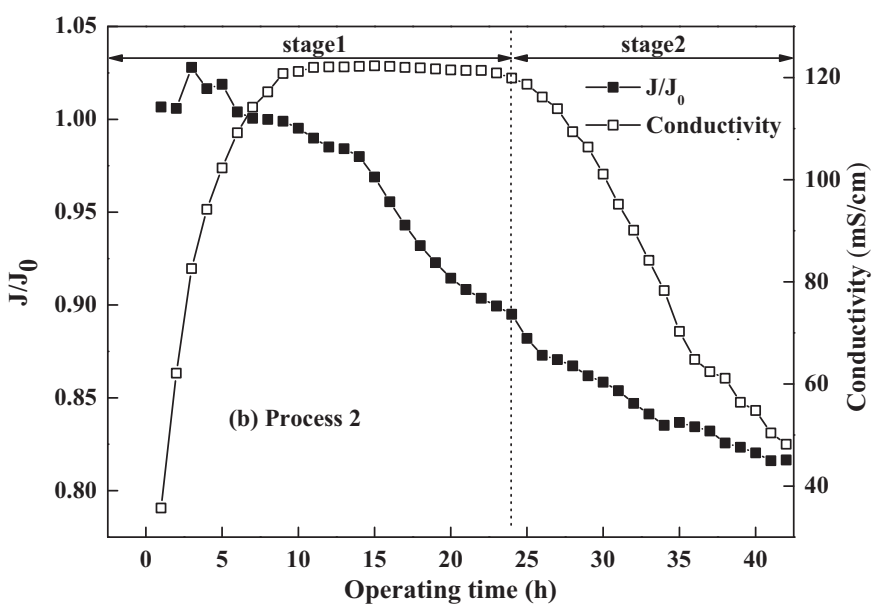

Fig. 8. Normalized flux $\left(J / J_{0}\right)$ and conductivity as a function of time in the MD units of two different processes (a) Process 1 and (b) Process 2.

\subsubsection{Surface morphology of the activated coke and membranes}

Fig. 9( $a$ and $b$ ) shows the SEM images of the activated coke before and after adsorption. The surface of raw activated coke appeared to be uneven and porous, indicating large available surface area for adsorption. After the adsorption, much smoother surface was observed, suggesting that most of the surface of the activated coke was occupied by the adsorbed organic and inorganic compounds from wastewater.

Fig. 9(c and d) and (e and f) shows the surface morphology of the RO and MD membranes after the experiments in two processes. For both the RO and MD membrane in Process 1 where no adsorption unit was presented, a thick cake layer was formed on the membrane surface, suggesting severe fouling which was confirmed by the larger flux decline in these two cases. On the other hand, when the adsorption pretreatment was applied, the cake layers appeared to be much thinner for both RO and MD membranes. Furthermore, the membrane fouling behavior was significantly alleviated, which was in good agreement with the results of flux decline in RO and MD units (the permeate fluxes of the RO and MD units increased by 


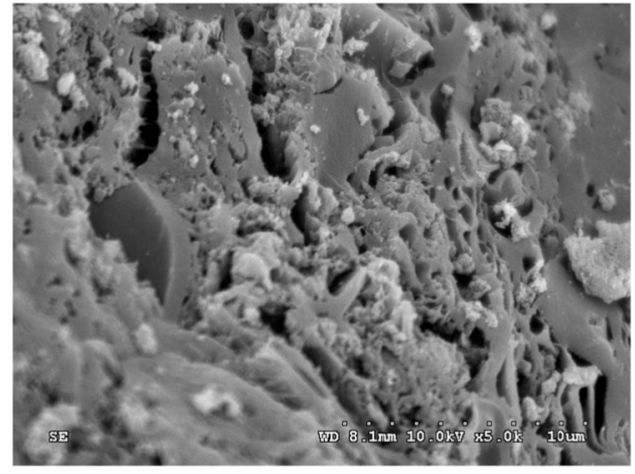

(a)

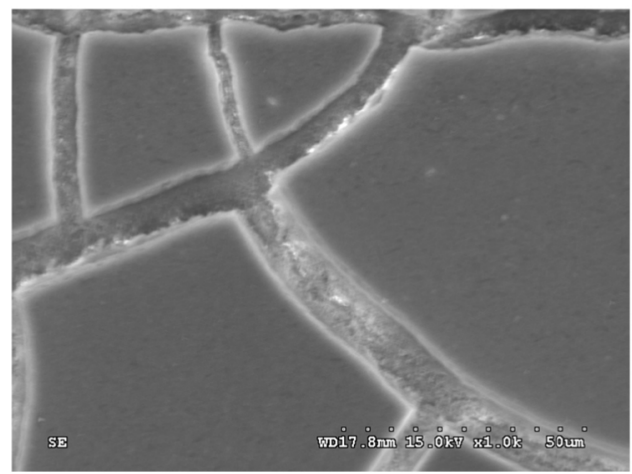

(c)

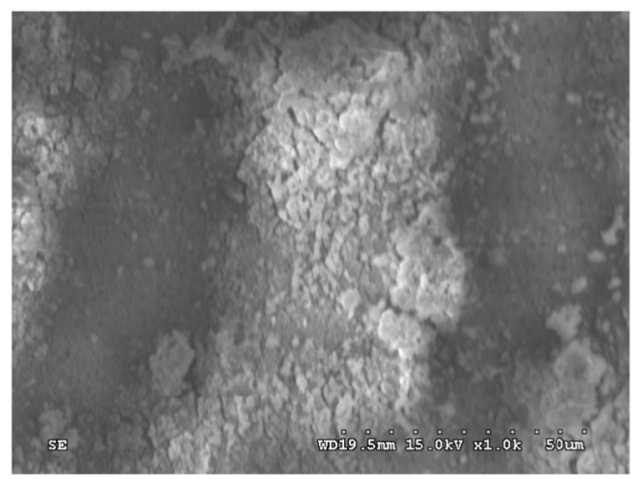

(e)

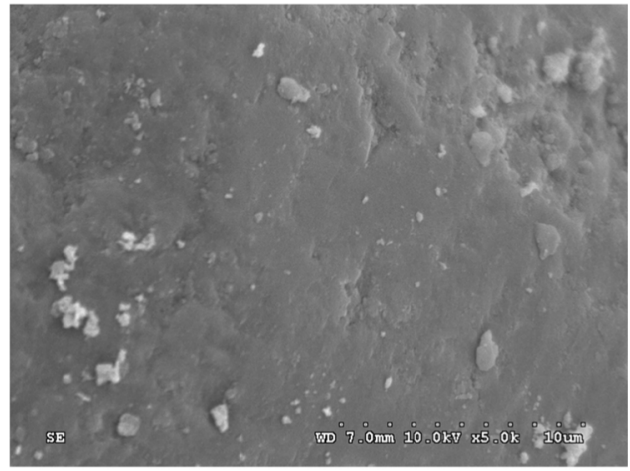

(b)

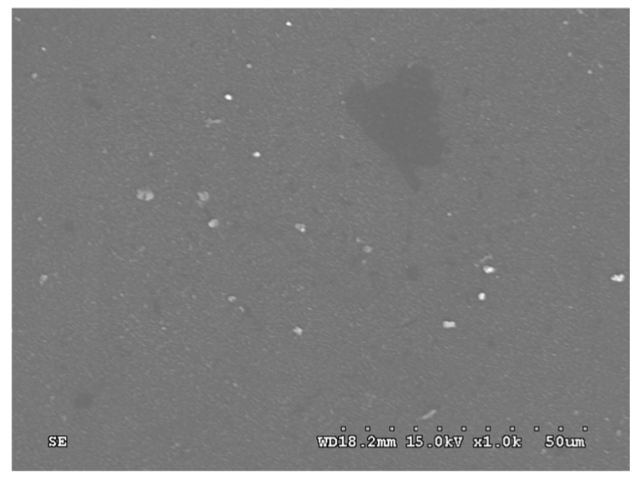

(d)

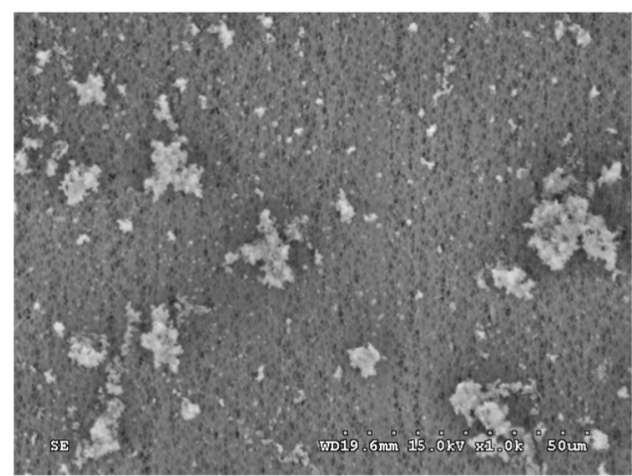

(f)

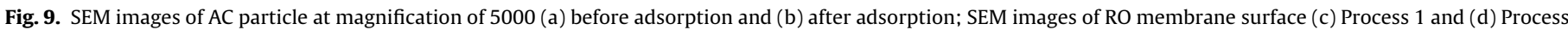
2; SEM images of MD membrane surface (e) Process 1 and (f) Process 2.

$21.9 \%$ and $23.1 \%$, respectively, when the adsorption unit was added in comparison with those of Process 1 ).

\section{Conclusions}

A novel integrated membrane system incorporated with an activated coke adsorption unit was proposed and examined with real coal gasification wastewater provided by a local coal gasification plant in China as influent. The effect of the additional adsorption unit on the contaminant removal and membrane fouling mitigation was systematically studied. The use of abundant and low-cost activated coke (provided by the same coal gasification plant) as adsorbent effectively removed majority of the organic matters presented in the wastewater which otherwise can be hardly removed by the conventional membrane systems. The FEEM, MWD, and GC-MS analysis further revealed that humic acid, fulvic acid, and heterocyclic compounds were mostly removed by the additional adsorption unit, most of which are commonly found as main contributors to the undesired membrane fouling phenomenon. As a result of such an efficient removal of these potential foulants, the integrated membrane system incorporated with adsorption unit displayed much better fouling resistance for 
all the membrane units integrated in the process (UF, RO, and $\mathrm{MD})$.

\section{Acknowledgments}

This work was supported by the National Science and Technology Major Project (No. 2012ZX07202006-003-2) and the National Natural Science Foundation of China (Grant No. 51378491).

\section{References}

[1] W. Chen, R. Xu, Clean coal technology development in China, Energy Pol. 38 (2010) 2123-2130.

[2] E. Shoko, B. McLellan, A. Dicks, J.D. da Costa, Hydrogen from coal: production and utilisation technologies, Int. J. Coal Geol. 65 (2006) 213-222.

[3] W. Zhang, M. Jun, Y. Shidong, T. Zhang, L. Yongfeng, Pretreatment of coal gasification wastewater by acidification demulsion, Chin. J. Chem. Eng. 14 (2006) 398-401.

[4] H. Gai, Y. Jiang, Y. Qian, A. Kraslawski, Conceptual design and retrofitting of the coal-gasification wastewater treatment process, Chem. Eng. J. 138 (2008) 84-94.

[5] Z. Wang, X. Xu, Z. Gong, F. Yang, Removal of COD, phenols and ammonium from Lurgi coal gasification wastewater using A 2 O-MBR system, J. Hazard. Mater. 235 (2012) 78-84.

[6] W. Wang, H. Han, M. Yuan, H. Li, F. Fang, K. Wang, Treatment of coal gasification wastewater by a two-continuous UASB system with step-feed for COD and phenols removal, Bioresour. Technol. 102 (2011) 5454-5460.

[7] Z. Wang, Z. Fan, L. Xie, S. Wang, Study of integrated membrane systems for the treatment of wastewater from cooling towers, Desalination 191 (2006) $117-124$.

[8] C.M. Tun, A.M. Groth, Sustainable integrated membrane contactor process fo water reclamation, sodium sulfate salt and energy recovery from industrial effluent, Desalination 283 (2011) 187-192

[9] E. Drioli, A. Criscuoli, E. Curcio, Integrated membrane operations for seawater desalination, Desalination 147 (2002) 77-81.

[10] E. El-Zanati, K. El-Khatib, Integrated membrane-based desalination system, Desalination 205 (2007) 15-25.

[11] S. Mondal, S.R. Wickramasinghe, Produced water treatment by nanofiltration and reverse osmosis membranes, J. Membr. Sci. 322 (2008) 162-170.

[12] E. Dialynas, E. Diamadopoulos, Integration of a membrane bioreactor coupled with reverse osmosis for advanced treatment of municipal wastewater Desalination 238 (2009) 302-311.

[13] C. Park, S.-W. Hong, T.H. Chung, Y.-S. Choi, Performance evaluation of pretreatment processes in integrated membrane system for wastewater reuse, Desalination 250 (2010) 673-676.

[14] J.-O. Kim, J.-T. Jung, J. Chung, Treatment performance of metal membrane microfiltration and electrodialysis integrated system for wastewater reclamation, Desalination 202 (2007) 343-350.
[15] B. Durham, M.M. Bourbigot, T. Pankratz, Membranes as pretreatment to desalination in wastewater reuse: operating experience in the municipal and industrial sectors, Desalination 138 (2001) 83-90.

[16] M. He Zhang, Q. Lin Zhao, X. Bai, Z. Fang Ye, Adsorption of organic pollutants from coking wastewater by activated coke, Colloid Surf. A-Physicochem. Eng. Asp. 362 (2010) 140-146.

[17] D. Guo, Q Shi, B. He, X. Yuan, Different solvents for the regeneration of the exhausted activated carbon used in the treatment of coking wastewater, J. Hazard. Mater. 186 (2011) 1788-1793.

[18] A.R. Shawwa, D.W. Smith, D.C. Sego, Color and chlorinated organics removal from pulp mills wastewater using activated petroleum coke, Water Res. 35 (2001) 745-749

[19] Y.M. Kim, D. Park, D.S. Lee, J.M. Park, Inhibitory effects of toxic compounds on nitrification process for cokes wastewater treatment, J. Hazard. Mater. 152 (2008) 915-921.

[20] M. Zhang, Q. Zhao, Z. Ye, Organic pollutants removal from 2,4,6-trinitrotoluene (TNT) red water using low cost activated coke, J. Environ. Sci. 23 (2011) 1962-1969.

[21] A. Wiessner, M. Remmler, P. Kuschk, U. Stottmeister, The treatment of a deposited lignite pyrolysis wastewater by adsorption using activated carbon and activated coke, Colloid Surf. A-Physicochem. Eng. Asp. 139 (1998) 91-97.

[22] W. Chen, P. Westerhoff, J.A. Leenheer, K. Booksh, Fluorescence excitation-emission matrix regional integration to quantify spectra for dissolved organic matter, Environ. Sci. Technol. 37 (2003) 5701-5710.

[23] P. Lai, H. Zhao, Z. Ye, J. Ni, Assessing the effectiveness of treating coking effluents using anaerobic and aerobic biofilms, Process Biochem. 43 (2008) 229-237.

[24] P. Lai, H.-Z. Zhao, C. Wang, J.-R. Ni, Advanced treatment of coking wastewater by coagulation and zero-valent iron processes, J. Hazard. Mater. 147 (2007) 232-239.

[25] D.J. Barker, D.C. Stuckey, A review of soluble microbial products (SMP) in wastewater treatment systems, Water Res. 33 (1999) 3063-3082.

[26] P. Lai, H.-Z. Zhao, M. Zeng, J.-R. Ni, Study on treatment of coking wastewater by biofilm reactors combined with zero-valent iron process, J. Hazard. Mater. 162 (2009) 1423-1429.

[27] C.Y. Tang, Y.-N. Kwon, J.O. Leckie, Fouling of reverse osmosis and nanofiltration membranes by humic acid-effects of solution composition and hydrodynamic conditions, J. Membr. Sci. 290 (2007) 86-94.

[28] S. Srisurichan, R. Jiraratananon, A. Fane, Humic acid fouling in the membrane distillation process, Desalination 174 (2005) 63-72

[29] D.C. Sioutopoulos, A.J. Karabelas, Correlation of organic fouling resistances in RO and UF membrane filtration under constant flux and constant pressure, J. Membr. Sci. 407 (2012) 34-46.

[30] Y. Song, J. Xu, Y. Xu, X. Gao, C. Gao, Performance of UF-NF integrated membrane process for seawater softening, Desalination 276 (2011) 109-116.

[31] A.S. Al-Amoudi, Factors affecting natural organic matter (NOM) and scaling fouling in NF membranes: a review, Desalination 259 (2010) 1-10.

[32] K. Karakulski, M. Gryta, Water demineralisation by NF/MD integrated processes, Desalination 177 (2005) 109-119. 